\title{
Editorial
}

\section{Hepatitis C in the Eastern Mediterranean Region} Gamal Esmat ${ }^{1}$

Hepatitis C virus (HCV) infection is still one of the major causes of mortality and morbidity worldwide and is the main cause of liver cirrhosis, hepatocellular carcinoma and liver transplantation in developing countries [1]. The World Health Organization (WHO) has estimated a 3\% worldwide prevalence of the virus affecting more than 170 million people worldwide [2].

A clear geographical distribution of the virus exists due to many factors. The Middle East region is the geographical area traditionally consisting of southwest Asia and parts of North Africa. This areashows a heterogeneous distribution of $\mathrm{HCV}$ with at least 23 million people estimated to have HCV infection in the countries of the Eastern Mediterranean Region of WHO [3]. This is close to the number of infected people in the Americas and Europe combined. The average overall prevalence in most countries of the Region ranges from $1 \%$ to $2 \%$ with the exception of Egypt which is considered to have the highest prevalence worldwide with an estimated $14.7 \%$ of the total population seropositive for HCV $[4,5]$. The epidemic of HCV in Egypt is always explained by the previous long use of parenteral antischistosomal treatment campaigns for more than 30 years; this could explain in the higher rates in the age group 40-60 years in comparison with younger age categories [6]. No published data are available about the prevalence and risk factors of HCV transmission in some countries of the Region.

HCV has six major genotypes and the genetic diversity of HCV has been clearly linked to the geographic distribution of the virus in different populations, as well as in specific risk groups. Genotype is of clinical importance because of the impact it may have on the response to the current standard therapy for $\mathrm{HCV}$, combined pegylated interferon and ribavirin. Genotype is also considered to be an important epidemiological marker as it may help trace the sources of infection and elucidate the possible modes of transmission [7]. The genotypes of HCV in Middle East countries take two main distribution patterns; the first is limited mostly to the Arab countries (except Jordan) with genotype 4 being predominant. The other pattern which exists in nonArab countries (Islamic Republic of Iran, Israel and Turkey) is characterized by the dominance of genotype 1 [8]. Although varying prevalence rates of genotype 4 have been reported in the Arab countries, it is noteworthy that genotype 4 is quasi-exclusive (93\%) in Egypt [9]. Jordan, the Arab country that is the exception to this rule, shows a heterogeneous distribution of genotypes with la the dominant subtype (40\%), followed by $1 \mathrm{~b}(33.3 \%)$ and genotype $4(26.6 \%)$ [10]. A clear indication of the existence of the 2 patterns of genotypes in Middle East countries came from a study conducted to investigate genotypes of HCV in the Gaza Strip and southern Israel. The most common genotypes found were type $1 \mathrm{~b}(62 \%)$ in southern Israel and type 4 (78\%) in the Gaza Strip, which is the same dominant genotype in Egypt [11]. Both prevalent genotypes in the region (4 and 1) were considered the genotypes most difficult to treat in terms of response to the standard therapy. Since the development of new antiviral drugs and the approval of these drugs for managing genotype 1 , response to treatment has improved for this genotype, leaving genotype 4 the most resistant type to treat [12].

The most challenging obstacles to managing $\mathrm{HCV}$ are the continuous transmission of infection due to lack of effective infection control measures and prevention programmes as well as the high cost of treatment. The financial burden of treatment in the Region is problematic in view of the limited resources of many of the countries. The expected directly acting antiviral drugs could add more to this in the near future. An example of a relatively integrated programme for managing $\mathrm{HCV}$ came from Egypt. In 2006, the Egyptian authorities launched the national control strategy for managing viral hepatitis. The programme aimed to improve access to HCV treatment through a specialized network of viral hepatitis treatment centres covering the entire country and providing antiviral treatment at very affordable prices to people in need. Despite success in improving access to treatment and delivery of treatment to almost 200000 people in the past few years, more programmes for preventing transmission and optimizing the treatment strategies provided are needed [13].

HCV remains a considerable challenge in the Middle East region imposing both a health and a financial burden and more efforts are required to highlight the problem and augment both prevention and treatment programmes. 


\section{References}

1. Sy T, Jamal MM. Epidemiology of hepatitis C virus (HCV) infection. International Journal of Medical Sciences, 2006, 3:41-46.

2. WHO. Global surveillance and control of hepatitis C. Report of a WHO Consultation organized in collaboration with the Viral Hepatitis Prevention Board, Antwerp, Belgium. Journal of Viral Hepatitis, 1999, 6:35-47.

3. The growing threats of hepatitis $B$ and $C$ in the Eastern Mediterranean Region: a call for action. Technical paper presented at the 56th Regional Committee for the Eastern Mediterranean, August 2009 (http://applications.emro.who.int/docs/EM_ RC56_3_en.pdf, accessed 20 July 2013).

4. Fallahian F, Najafi A. Epidemiology of Hepatitis C in the Middle East. Saudi Journal of Kidney Diseases and Transplantation, 2011, 22(1):1-9.

5. El-Zanaty, F, Way A. Egypt Demographic and Health Survey 2008. Cairo, Egypt: Ministry of Health, El-Zanaty and Associates, and Macro International, 2009 (http://www.measuredhs.com/pubs/pdf/FR220/FR220.pdf, accessed 10 July 2011).

6. Mohamed MK et al. HCV-related morbidity in a rural community of Egypt. Journal of Medical Virology, 2006, 78:1185-1189.
7. Nguyen MH, Keeffe EB. Epidemiology and treatment outcomes of patients with chronic hepatitis $\mathrm{C}$ and genotypes 4 to 9. Reviews in Gastroenterological Disorders, 2004, 4(Suppl. 1):S14-S21.

8. Ramia S, Eid-Fares J. Distribution of hepatitis C virus genotypes in the Middle East. International Journal of Infectious Diseases, 2006, 10:272-277.

9. Sievert $\mathrm{W}$ et al. A systematic review of hepatitis $\mathrm{C}$ virus epidemiology in Asia, Australia and Egypt. Liver International, 2011, 31(Suppl. 2):61-80.

10. Bdour $\mathrm{S}$. Hepatitis $\mathrm{C}$ virus infection in Jordanian hemodialysis units: serological diagnosis and genotyping. Journal of Medical Microbiology, 2002, 51(8):700-704.

11. Shemer-Avni $\mathrm{Y}$ et al. Hepatitis $\mathrm{C}$ virus infection and genotypes in Southern Israel and the Gaza Strip. Journal of Medical Virology, 1998, 56:230-233.

12. Esmat $\mathrm{G}$ et al. The future for the treatment of genotype 4 chronic hepatitis C. Liver International, 2012, 32(Suppl. 1):146-150.

13. Progress toward prevention and control of hepatitis $C$ virus infection Egypt, 2001-2012. MMWR. Morbidity and Mortality Weekly Report, 2012, 61(29):545-549. 